\title{
A Healthy Young Woman with Acute Respiratory Distress Syndrome: an unfamiliar face of a familiar disease
}

Fereshte Sheybani ${ }^{1}$, Hamid Reza Naderi ${ }^{2}$, Ahmad Bagheri Moghaddam ${ }^{3}$, Bezat Amiri ${ }^{4}$

${ }^{1}$ Fereshte Sheybani, Assistant Professor in Infectious Diseases, Faculty of Medicine, Mashhad University of Medical Sciences, Mashhad, Iran

${ }^{2}$ Hamid Reza Naderi, Associate Professor in Infectious Diseases, Faculty of Medicine, Mashhad University of Medical Sciences, Mashhad, Iran

${ }^{3}$ Ahmad Bagheri Moghaddam, Assistant Professor in Internal Medicine, Faculty of Medicine, Mashhad University of Medical Sciences, Mashhad, Iran

${ }^{4}$ Bezat Amiri, Resident of Infectious Diseases, Faculty of Medicine, Mashhad University of Medical Sciences, Mashhad, Iran

Type of article: Case report

\begin{abstract}
The presented case features a rare manifestation of pulmonary tuberculosis in a previously healthy young woman who had acute presentation of tuberculous pneumonia complicated by acute respiratory distress syndrome. In developing countries, mycobacterium tuberculosis is an important cause of community-acquired pneumonia (CAP). TB can present as an acute process and should be included in the differential diagnosis of CAP. This case is special in its manifestation from several clinical perspectives, including the lack of an underlying medical condition or immune defect and the development of acute respiratory distress syndrome (ARDS) in non-miliary and non-disseminated tuberculosis. In conclusion, the diagnosis of TB should be considered in all patients who present with CAP in endemic regions.
\end{abstract}

Keywords: Tuberculosis; Community-acquired pneumonia; Acute respiratory distress syndrome (ARDS)

\section{Introduction}

Although S. pneumoniae is the most common cause of community-acquired pneumonia (CAP) in many countries, there are considerable geographic differences in the incidence of other pathogens. M. tuberculosis is an important cause of CAP in developing countries (1). Tuberculosis (TB) is often overlooked as a cause of CAP, particularly when it presents as an acute illness (2). Although the presentation of pulmonary TB as acute pneumonia is not unusual, its manifestation as acute respiratory distress syndrome (ARDS) is rare. ARDS is a severe form of diffuse alveolar injury. The American-European Consensus Conference (AECC) (1994) defined ARDS as an acute condition characterized by bilateral pulmonary infiltrates and severe hypoxemia in the absence of evidence for cardiogenic pulmonary edema. The severity of hypoxemia necessary to make the diagnosis of ARDS was defined by the ratio of the partial pressure of oxygen in the patient's arterial blood $(\mathrm{PaO} 2)$ to the fraction of oxygen in the inspired air $\left(\mathrm{FIO}_{2}\right)$. ARDS was defined by a $\mathrm{PaO}_{2} / \mathrm{FIO}_{2}$ ratio of less than 200 , and, in acute lung injury (ALI), by a ratio less than 300 (3). Recently, a panel of experts redefined the definition (Berlin definition) (2011) and categorized ARDS into three levels: mild $\left(\mathrm{PaO}_{2} / \mathrm{FIO}_{2}\right.$ 200-300), moderate ( $\mathrm{PaO} / \mathrm{FIO} 2$ 100-200), and severe $\left(\mathrm{PaO}_{2} / \mathrm{FIO}_{2} \leq 100\right)$ (4). Even though ALI and ARDS are well recognized complications in patients with severe TB, such as miliary TB or TB bronchopneumonia, sparse epidemiological data are available on this entity. Most patients who develop ALI/ARDS have underlying chronic medical conditions or HIV infections, and their diagnoses were delayed (5). Herein, we present a rare case of a previously healthy young patient with acute pulmonary tuberculosis in the form of TB pneumonia that was complicated by ARDS.

\section{Corresponding author:}

Associate Professor Dr. Hamid Reza Naderi, Faculty of Medicine, Mashhad University of Medical Sciences, Mashhad, Iran. Tel: +98.5138022408, Fax:+98.5138591057, Email: naderihr@mums.ac.ir

Received: February 10, 2016, Accepted: May 16, 2016, Published: October 2016

iThenticate screening: May 16, 2016, English editing: July 27, 2016, Quality control: September 01, 2016

(C) 2016 The Authors. This is an open access article under the terms of the Creative Commons Attribution-NonCommercialNoDerivs License, which permits use and distribution in any medium, provided the original work is properly cited, the use is non-commercial and no modifications or adaptations are made. 


\section{Case report}

\subsection{Clinical presentation}

A 21-year-old woman, a radiology technician student, presented with acute respiratory failure due to progressive respiratory symptoms, including productive cough and dyspnea that started seven days before presentation. At the time of her admission to the hospital, she had central and peripheral cyanosis and severe respiratory distress. Her initial vital signs were as follows: $\mathrm{BP}=110 / 70 \mathrm{mmHg}, \mathrm{HR}=122 / \mathrm{min}, \mathrm{RR}=40 / \mathrm{min}$, and temperature $=40{ }^{\circ} \mathrm{C}$. Oxygen saturation in the room air was $64 \%$. There were no mucocutaneous lesions, peripheral adenopathies, or cardiac murmurs. Lung examination revealed bilateral coarse crackles. Because she presented during the influenza season and because the symptoms were compatible with severe pneumonia, a broad spectrum of antibiotics and oseltamivir were started, and she was intubated and received mechanical ventilation. She was transferred to the intensive care unit (ICU).

\subsection{History}

There was no history of previous illness or recent travel and no family history of note. She takes no medications.

\subsection{Laboratory and imaging findings}

Arterial blood gas revealed hypoxemia $\left(\mathrm{PaO}_{2}=24.3 \mathrm{mmHg}\right)$, hypercapnia $\left(\mathrm{PaCo}_{2}=55.1 \mathrm{mmHg}\right)$, and respiratory acidosis $\left(\mathrm{pH}=7.25, \mathrm{HCO}_{3}: 26\right)$. Other laboratory test results are shown in the Table 1 . The HIV test was negative. Based on an initial $\mathrm{PaO}_{2} / \mathrm{FiO}_{2}$ ratio of less than 100 on ventilator setting that included PEEP and characteristic diffuse bilateral infiltrates on chest X-ray (Figure 1), acute respiratory distress syndrome (ARDS) was diagnosed. Echocardiography was normal. Gram staining of deep tracheal aspirate revealed scant polymorphonuclear cells with no organisms. Ziehl-Neelsen staining indicated numerous acid fast bacilli (Figure 2). Bacterial and fungal cultures of respiratory secretions showed no growth after seven days. A real-time PCR test on respiratory specimens for influenza $\mathrm{A}$ and $\mathrm{B}$ was negative.

Table 1. Biochemical results of the patient

\begin{tabular}{|l|l|l|}
\hline Test results & Patient's results & Normal range \\
\hline Hemoglobin & $11.1 \mathrm{~g} / \mathrm{dL}$ & $12.30-15.30 \mathrm{mg} / \mathrm{dL}$ \\
\hline White blood cell counts & $12.2 \times 10^{9}$ cells/L with $83.5 \%$ neutrophils & $4.4-11.3 \times 10^{9}$ cells/L \\
\hline Platelet counts & $323 \times 10^{9}$ cells/L & $150-450 \times 10^{9}$ cells/L \\
\hline Aspartate aminotransferase & $37 \mathrm{U} / \mathrm{L}$ & $5-40 \mathrm{U} / \mathrm{L}$ \\
\hline Alanine aminotransferase & $17 \mathrm{U} / \mathrm{L}$ & $5-40 \mathrm{U} / \mathrm{L}$ \\
\hline Alkaline phosphatase & $130 \mathrm{IU} / \mathrm{L}$ & $64-306 \mathrm{U} / \mathrm{L}$ \\
\hline Lactate dehydrogenase & $350 \mathrm{U} / \mathrm{L}$ & $100-500 \mathrm{U} / \mathrm{L}$ \\
\hline Highly sensitive C-reactive protein & $18.39 \mu \mathrm{g} / \mathrm{L}$ & up to $5 \mu \mathrm{g} / \mathrm{L}$ \\
\hline ESR & $9 \mathrm{~mm} / \mathrm{h}$ & $0-20 \mathrm{~mm} / \mathrm{h}$ \\
\hline
\end{tabular}

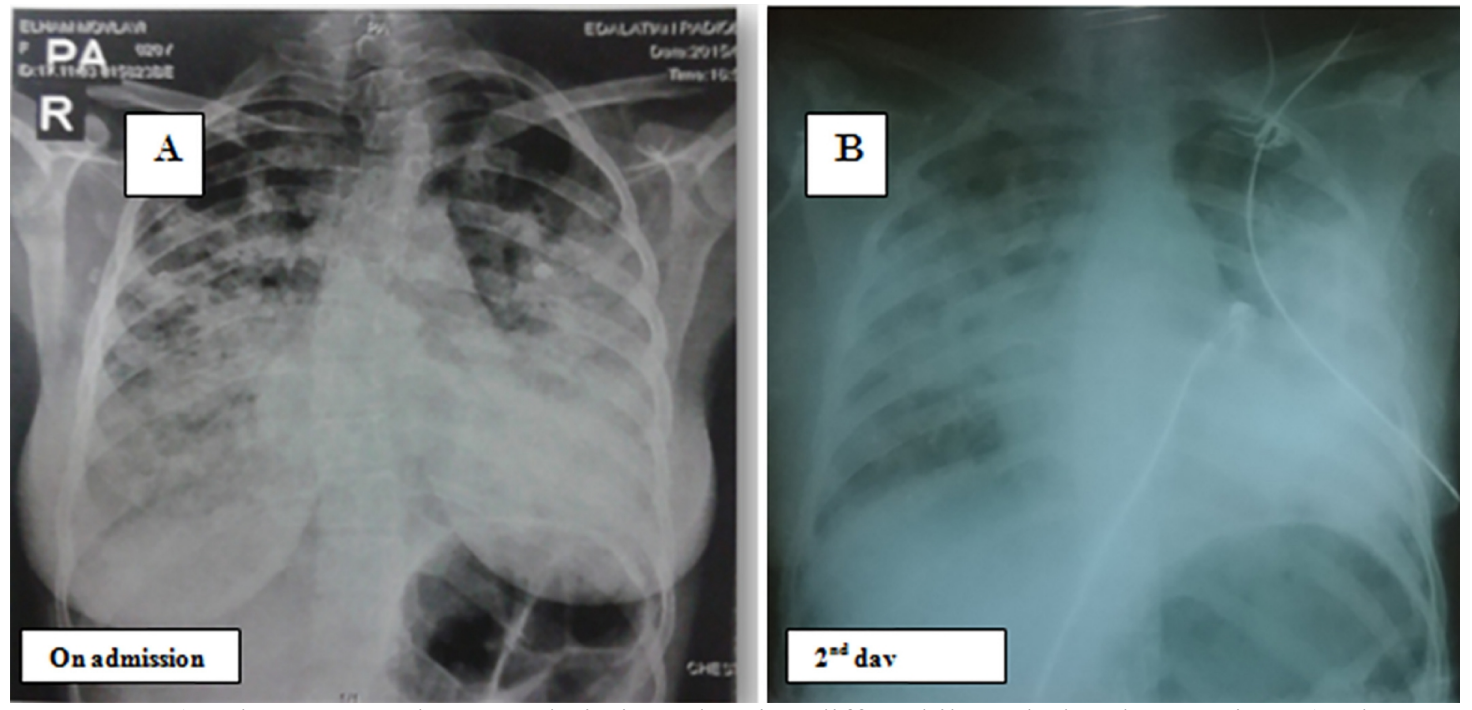

Figure 1. A): Chest $\mathrm{x}$-ray taken on admission, showing diffuse bilateral alveolar opacity; B) Chest $\mathrm{x}$-ray taken on post-admission day two showed further progression of extensive lung infiltrates 


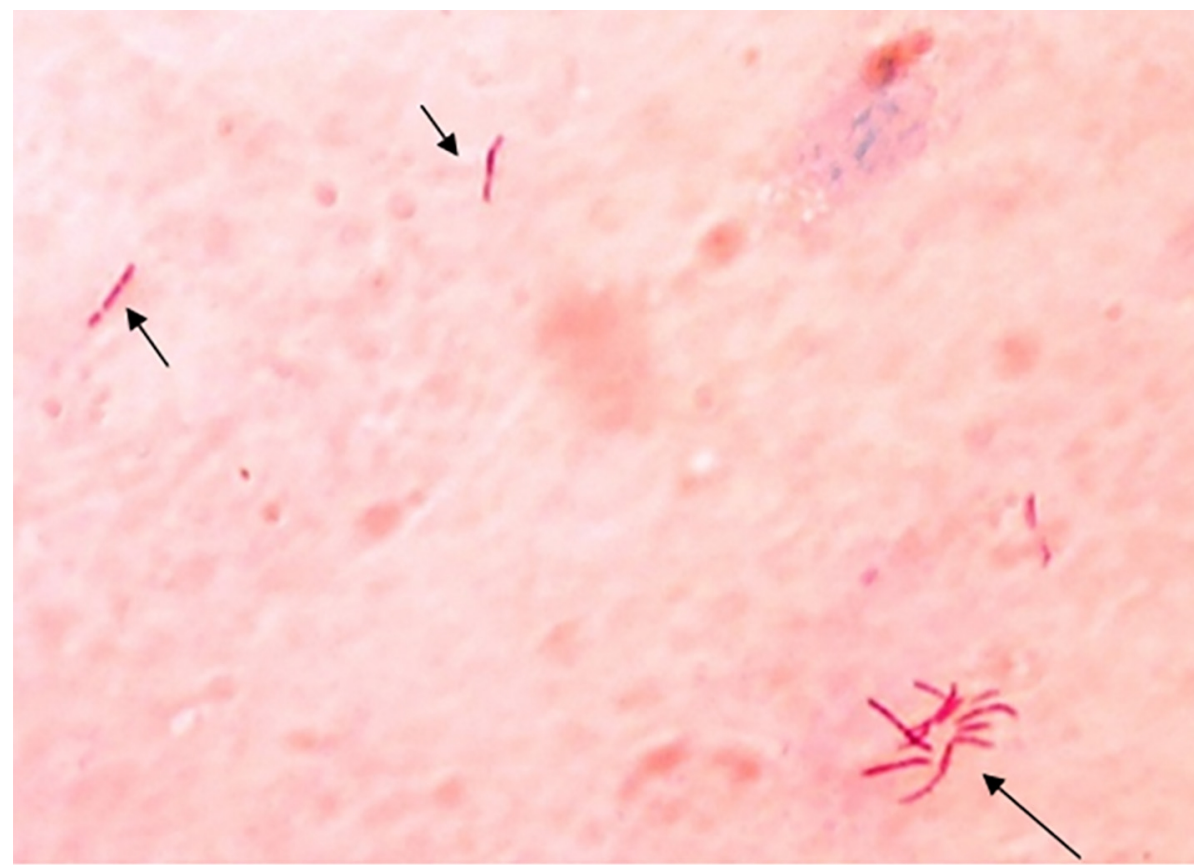

Figure 2. Ziehl-Neelsen staining of deep tracheal aspirate showed numerous acid fast bacilli and scant polymorphonuclears

\subsection{Treatment and follow-up}

Accordingly, diagnosis of ARDS secondary to pulmonary tuberculosis was made, and the patient received antituberculous drugs and intravenous hydrocortisone $100 \mathrm{mg}$ three times per day. The patient continued to improve gradually during the first week, and she was successfully weaned and extubated on her seventh day in the hospital. Her chest infiltrates gradually resolved during the first week, but left lower- and mid-zone consolidation remained (Figure 3). She remained hospitalized in the infectious ward and received $\mathrm{O}_{2}$ therapy plus anti-tuberculous drugs for another 15 days. Corticosteroids were stopped. During this period she remained mildly tachypnic and hypoxic. On the $24^{\text {th }}$ day after presentation, she was discharged with stable vital signs and no hypoxia in the room air. Antituberculous drugs were planned to be continued for total of six months.
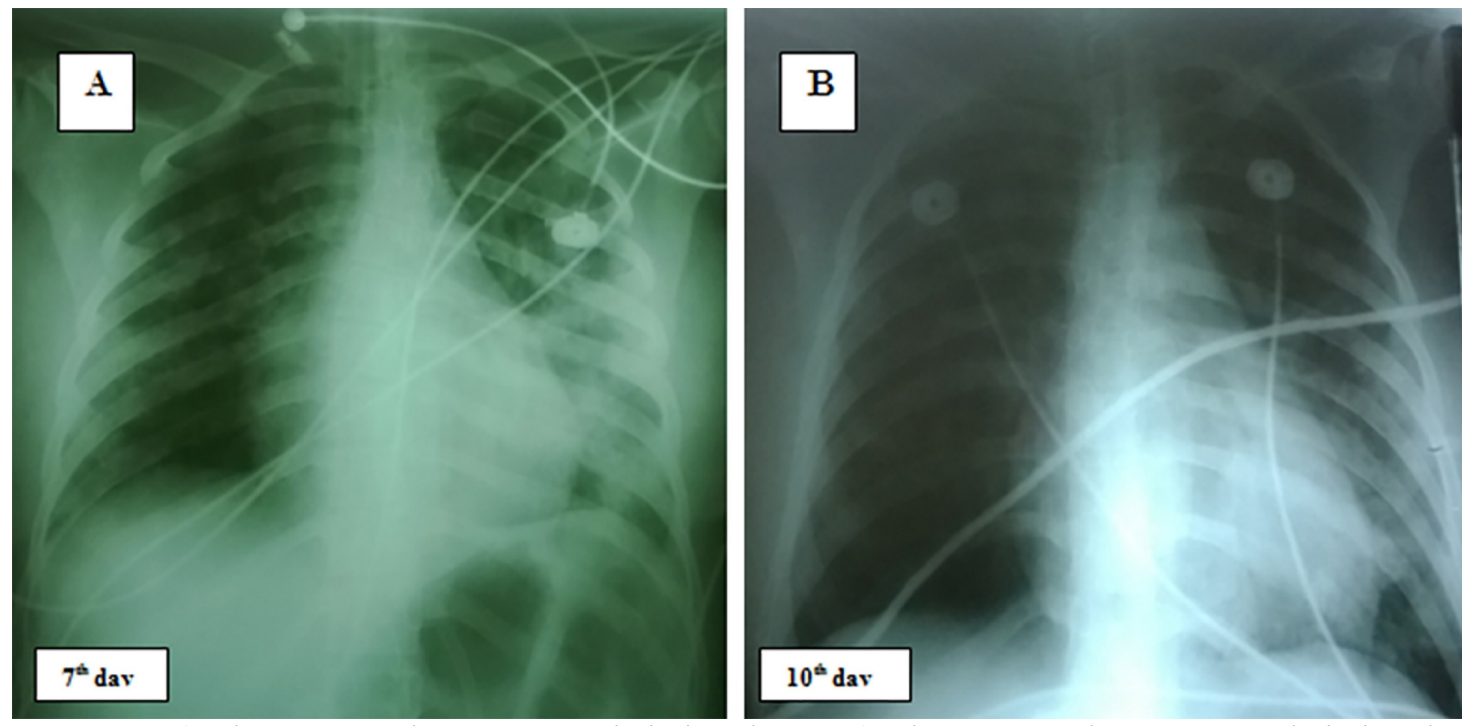

Figure 3. A) Chest $\mathrm{x}$-ray taken on post-admission day 7; B) Chest $\mathrm{x}$-ray taken on post-admission day 10: The Xrays show the resolution of extensive bilateral infiltrate, except for the pneumonic consolidation in the left lower lobe. 


\section{Discussion}

This case features a rare manifestation of pulmonary tuberculosis in a previously healthy young woman with acute presentation of tuberculous pneumonia complicated by ARDS. Tuberculous pneumonia is defined as nodular lesions resulting from air-space consolidation due to endobronchial spread to lobar or multilobar locations (5). M. tuberculosis is an important cause of community-acquired pneumonia (CAP) in developing countries. TB can present as an acute process and should be included in the differential diagnosis of CAP. It may mimic classic bacterial pneumonia or masquerade as an atypical pneumonia, with non-productive cough and systemic symptoms. Both primary and reactivation TB can cause acute manifestations (2). Missed diagnosis is common, as illustrated in report from Baltimore in which 16 of 33 patients (48\%) with culture-confirmed pulmonary TB were treated initially for presumed CAP (1). The incidence of TB being diagnosed among patients presenting with clinical and radiological signs of a CAP has varied in different series. Previously, studies from China, Japan, Kenya, and Sub Saharan Africa also demonstrated high prevalence of pulmonary TB (9-20.5\%) in patients who presented with CAP (6-11). M. tuberculosis was the second most common pathogen (12\%) identified in the study performed by Levy et al. (12) in Hong Kong. In the latter study, only patients who presented with features of acute pneumonia were included; those with chronic illness or typical radiologic changes suggestive of TB were excluded. A similar high incidence of TB (10\%) among subjects presenting with acute pneumonia was reported in France (7). Although presentation of pulmonary TB as acute pneumonia is not unusual, its manifestation as ARDS is rare. This complication is associated with a very high mortality (40-80\%) despite treatment (5). Even in a large study from India that was conducted by Agarwal et al, TB accounted for only 4.9\% of patients ( 9 of 187) who were admitted with a diagnosis of ARDS over a 7-year period, of whom two patients died. The lower mortality rate in this study could be attributed to the fact that all subjects were started empirically on anti-TB therapy with the median time to initiation of therapy being three days. Tracheal aspirate sent for Ziehl-Neelsen staining did not indicate that there were acid-fast bacilli in any of the patients of this study (13). In another study by Sharma et al. in India, of 2,733 TB patients treated during 1980-2003, 29 (1.06\%, i.e., 1.21 patients/year) developed ARDS (14). Another large retrospective study conducted by Deng et al. in China over a five-year period (2006-2010) showed that, among 16,238 patients who were admitted to the respiratory departments with a diagnosis of pulmonary TB, 471 patients were diagnosed as having miliary TB, of whom 85 developed ARDS and were admitted to the ICU during the study period. The mortality rate in this study was $47.1 \%$, and the mean duration of mechanical ventilation was $8.5 \pm 3.0$ days in all patients (15). Another study from South Korea described 67 patients with ARDS caused by miliary TB admitted to the ICU during 1999-2008. All-cause mortalities in the ICU and the hospital were 58.2 and 61.2\%, respectively. In their study, $28.4 \%$ of the patients were older than 71 , but clinical outcomes in these patients did not differ significantly from outcomes in younger patients (16). Feng et al. (17) found that higher PSI scores were independently associated with the presence of concomitant pulmonary TB in both health care associated pneumonia (HCAP) and CAP patients. In the study performed by Levy et al. (18), the incidence rate of $1.5 \%$ was reported for acute respiratory failure among hospitalized patients who presented with tuberculous CAP. Although ARDS invariably occurs in patients with severe TB, such as miliary TB or TB bronchopneumonia (5), its occurrence in tuberculous pneumonia and cavitary pulmonary TB also was described (5). In the study of Agarwal et al., radiography of eight of nine patients with TB and ARDS revealed miliary nodules, and consolidation was observed in only one patient (13). Seven out of 29 patients with TB and ARDS in the study of Sharma et al. had pulmonary TB, and 22 had miliary TB (14). Several predisposing factors for development of ARDS in TB patients and several prognostic factors in these patients have been described. According to the study of Deng et al., the duration of time to diagnosis, time from diagnosis to mechanical ventilation, and time to anti-tuberculosis therapy were significantly shorter in survivors than for non-survivors. Diabetes mellitus, increased AST, ALT, and D-dimer, decreased hemoglobin, and albumin were found to be independent predictors of the development of ARDS in the setting of miliary TB (15). In the study reported by Sharma et al., the presence of miliary TB, duration of illness beyond 30 days at presentation, absolute lymphocyte count less than $1625 / \mathrm{mm}^{3}$ and serum ALT greater than 100 IU/1 were independent predictors of the development of ARDS. Patients with APACHE II scores $>18$, those with APACHE II scores $<18$ in the presence of hyponatraemia, and those with $\mathrm{PaO}_{2} / \mathrm{FIO}_{2}$ ratios $<108.5$ were likely to die (14). Lee et al. showed that the Sequential Organ Failure Assessment (SOFA) score on the day that ARDS is diagnosed is a valuable prognostic indicator (16). The case presented is special in its manifestation from several clinical perspectives, including lack of underlying medical condition or immune defect and development of ARDS in nonmiliary and non-disseminated tuberculosis. In conclusion, the diagnosis of TB should be considered in all patients who present with CAP in our region. It has been suggested that, in a patient with unexplained ARDS, a history of fever of more than 15 days duration and elevation of serum alkaline phosphatase should arouse the suspicion of disseminated TB as the underlying cause (5). It also has been suggested that, in patients with ARDS of obscure 
etiology where the clinical features suggest TB as the inciting cause, anti-TB therapy should be started empirically, and the diagnosis actively pursued later (13).

\section{Conclusions}

Both primary and reactivation TB may present as an acute illness and mimic CAP. As a result of the impressive mimicry of TB, the diagnosis must be considered, at least initially, in all cases of acute pneumonitis, especially in regions where tuberculosis is endemic.

\section{Acknowledgments:}

The authors appreciate the sincere efforts of all the hospital and ICU staff members who took care of the patient properly. Without the skills and serenity of Ms. Azar Ashour, the microbiology laboratory technician, who made the diagnosis so promptly, this report would not exist.

\section{Conflict of Interest:}

There is no conflict of interest to be declared.

\section{Authors' contributions:}

All authors contributed to this project and article equally. All authors read and approved the final manuscript.

\section{References:}

1) Dooley KE, Golub J, Goes FS, Merz WG, Sterling TR. Empiric treatment of community-acquired pneumonia with fluoroquinolones, and delays in the treatment of tuberculosis. Clin Infect Dis. 2002; 34(12): 1607-12. PMID: 12032896.

2) Schlossberg D. Acute tuberculosis. Infect Dis Clin North Am. 2010; 24(1): 139-46. doi: 10.1016/j.idc.2009.10.009. PMID: 20171549.

3) Bernard GR, Artigas A, Brigham KL, Carlet J, Falke K, Hudson L, et al. The American-European Consensus Conference on ARDS. Definitions, mechanisms, relevant outcomes, and clinical trial coordination. Am J Respir Crit Care Med. 1994; 149(3 Pt 1): 818-24. doi: 10.1164/ajrccm.149.3.7509706. PMID: 7509706.

4) ARDS Definition Task Force, Ranieri VM, Rubenfeld GD, Thompson BT, Ferguson ND, Caldwell E, et al. Acute respiratory distress syndrome: the Berlin Definition. JAMA. 2012; 307(23): 2526-33. doi: 10.1001/jama.2012.5669a. PMID: 22797452.

5) Karnad DR, Guntupalli KK. Tuberculosis and Acute Lung Injury. In: Tuberculosis. 2nd Edition. Editors: SK Sharma \& A Mohan. Jaypee Brothers Medical Publishers, New Delhi, India. 2009; 532-40. doi: 10.5005/jp/books/10992-36.

6) Kaplan V, Angus DC, Griffin MF, Clermont G, Scott Watson R, Linde-Zwirble WT. Hospitalized community-acquired pneumonia in the elderly: age- and sex-related patterns of care and outcome in the United States. Am J Respir Criti Care Med. 2002; 165(6): 766-72. PMID: 11897642.

7) Gatey C, Tattevin P, Rioux C, Ducot B, Meyer L, Bouvet E. Impact of early chest radiography and empirical antibiotherapy on delay in the diagnosis of pulmonary tuberculosis. Med Mal Infect. 2012; 42(3): 110-3. doi: 10.1016/j.medmal.2011.12.003. PMID: 22398329.

8) Nyamande K, Lalloo UG, John M. TB presenting as community-acquired pneumonia in a setting of high TB incidence and high HIV prevalence. Int J Tuberc Lung Dis. 2007; 11(12): 1308-13. PMID: 18034951.

9) Asnis DS, Cherian S, Sun T, Shrestha S, Santucci T Jr. Pulmonary tuberculosis presenting as communityacquired pneumonia. Clin Infect Dis. 2002; 35(12): 1574-5. PMID: 12471584.

10) Scott JA, Hall AJ, Muyodi C, Lowe B, Ross M, Chohan B, et al. Aetiology, outcome, and risk factors for mortality among adults with acute pneumonia in Kenya. Lancet. 2000; 355(9211): 1225-30. doi: 10.1016/S0140-6736(00)02089-4. PMID: 10770305.

11) Naderi H, Sheybani F, Sarvghad M, Meshkat Z, Jabbari Nooghabi M. Etiological Diagnosis of Community-Acquired Pneumonia in Adult Patients: A Prospective Hospital-Based Study in Mashhad, Iran. Jundishapur J Microbiol. 2015; 8(8): e22780. doi: 10.5812/jjm.22780. PMID: 26464771, PMCID: PMC4600341.

12) Lévy M, Dromer F, Brion N, Leturdu F, Carbon C. Community-acquired pneumonia. Importance of initial noninvasive bacteriologic and radiographic investigations. Chest. 1988; 93(1): 43-8. PMID: 3275531.

13) Agarwal R, Gupta D, Aggarwal AN, Behera D, Jindal SK. Experience with ARDS caused by tuberculosis in a respiratory intensive care unit. Intensive Care Med. 2005; 31(9): 1284-7. PMID: 16007416. 
14) Sharma SK, Mohan A, Banga A, Saha PK, Guntupalli KK. Predictors of development and outcome in patients with acute respiratory distress syndrome due to tuberculosis. Int J Tuberc Lung Dis. 2006; 10(4): 429-35. PMID: 16602408.

15) Deng W, Yu M, Ma H, Hu LA, Chen G, Wang Y, et al. Predictors and outcome of patients with acute respiratory distress syndrome caused by miliary tuberculosis: a retrospective study in Chongqing, China. BMC Infect Dis. 2012; 12: 121. doi: 10.1186/1471-2334-12-121. PMID: 22607610, PMCID: PMC3407496.

16) Lee K, Kim JH, Lee JH, Lee WY, Park MS, Kim JY, et al. Acute respiratory distress syndrome caused by miliary tuberculosis: a multicentre survey in South Korea. Int J Tuberc Lung Dis. 2011; 15(8): 1099-103. doi: 10.5588/ijtld.10.0557. PMID: 21740675.

17) Feng JY, Fang WF, Wu CL, Yu CJ, Lin MC, Ku SC, et al. Concomitant pulmonary tuberculosis in hospitalized healthcare-associated pneumonia in a tuberculosis endemic area: a multi-center retrospective study. PLoS One. 2012; 7(5): e36832. doi: 10.1371/journal.pone.0036832. PMID: 22629334, PMCID: PMC3358294.

18) Levy H, Kallenbach JM, Feldman C, Thorburn JR, Abramowitz JA. Acute respiratory failure in active tuberculosis. Crit Care Med. 1987; 15(3): 221-5. doi: 10.1371/journal.pone.0036832. PMID: 3469061. 